\title{
EFFECTS OF BUFLOMEDIL AND PENTOXIFYLLINE ON HAMSTER SKIN-FLAP MICROCIRCULATION: PREDICTION OF FLAP VIABILITY USING ORTHOGONAL POLARIZATION SPECTRAL IMAGING
}

\author{
Denise Salles Coelho da Mota, Eliane Furtado, Daniel Alexandre Bottino, Eliete \\ Bouskela
}

doi: $10.1590 / \mathbf{S 1 8 0 7 - 5 9 3 2 2 0 0 9 0 0 0 8 0 0 0 1 5}$

\begin{abstract}
Coelho da Mota DS, Furtado E, Bottino DA, Bouskela E. Effects of buflomedil and entoxifylline on hamster skin-flap microcirculation: prediction of flap viability using orthogonal polarization spectral imaging. Clinics. 2009;64(8):797-802.
\end{abstract}

OBJECTIVE: This study investigated the effects of buflomedil and pentoxifylline, both of which are used in reconstructive surgery of hamster skin flap microcirculation, and evaluated the skin flap survival rate by orthogonal polarization spectral imaging. METHOD: Twenty-four adult male Syrian golden hamsters were divided into three groups: a control (C, $0.1 \mathrm{ml} 0.9 \%$ saline), buflomedil (B, $3 \mathrm{mg} / \mathrm{kg} /$ day), and pentoxifylline group (P, $14.5 \mathrm{mg} / \mathrm{kg} / \mathrm{day})$. Treatments administered intraperitoneally were initiated 1 hour before skin flap preparation and continued for 7 days post-operatively at 12-hour intervals. Preparations (skin flaps) were divided into 12 fields, which were organized into six bands. Functional capillary density (FCD, in $\left.\mathrm{mm} / \mathrm{mm}^{2}\right)$, distance from the skin flap base to blood flow cessation (Dist ${ }_{\text {with flow }}$, in $\mathrm{cm}$ ), percentage of viable skin (VA, in\%), and qualitative analysis of blood flow by orthogonal polarization spectral imaging were performed at 1 and 24 hours and on the seventh post-operative day.

RESULT: Bands IV, V, and VI presented no flow independent of time. The functional capillary density group B was higher than that of groups $\mathrm{C}$ and $\mathrm{P}$, primarily after 24 hours. All groups showed an increase in D with time but reached similar final distances $(\mathrm{C}=2.73, \mathrm{~B}=2.78$ and $\mathrm{P}=2.70 \mathrm{~cm})$. Moreover, the percentage of viable areas remained at approximately $50 \%$. The orthogonal polarization spectral imaging was useful to assess viability by counting fields with and without blood flow.

CONCLUSIONS: Functional capillary density values were higher in the buflomedil group compared to the control and pentoxifylline groups in this model. Functional capillary density did not influence D or the percentage of VA, and the technique showed favorable potential to assess/predict the viability of skin flaps within $1 \mathrm{~h}$ after surgery.

KEYWORDS: OPS; Buflomedil; Pentoxifylline; Skin flap; Microcirculation.

\section{INTRODUCTION}

Skin flap necrosis is a serious concern in reconstructive surgery. The surgical procedure used to create flaps involves tissue damage because some areas may exceed the territory supplied by a given blood vessel, leading to several degrees of ischemia. ${ }^{1}$ Moreover, microvascular perfusion is seriously impaired with failing procedures. ${ }^{2,3}$ Vasoactive drugs can be

Laboratório de Pesquisas Clínicas e Experimentais em Biologia Vascular, Departamento de Ciências Fisiológicas, Universidade do Estado do Rio de Janeiro - Rio de Janeiro/RJ, Brazil

E-mail: dbottino1@yahoo.com.br

Tel: 55212587.7771

Received for publication on March 24, 2009

Accepted for publication on May 19, 2009 used to ameliorate the ischemia process and extend survival. Buflomedil and pentoxifylline have often been used in the treatment of peripheral artery disease and microcirculatory deficit, resulting in improved flap viability. ${ }^{4-7}$

Buflomedil is an alpha-receptor blocking agent and a non-specific calcium antagonist. It can also inhibit platelet aggregation, increase red blood cell deformability, and decrease peripheral vascular resistance, thus restoring microcirculatory perfusion. ${ }^{8}$ Buflomedil appears to improve nutritional blood flow in ischemic tissue in peripheral or cerebral diseases. Consequently, it increases walking distances in patients suffering from intermittent claudication. ${ }^{9}$ Pentoxifylline is a xanthine-derived phosphodiesterase inhibitor that enhances cAMP levels, theoretically via the same actions as buflomedil, ${ }^{10}$ i.e., it has beneficial effects on 
white blood cell function and hemorheological conditions. ${ }^{11}$ The effects of buflomedil and pentoxifylline administration on functional capillary density, tissue viability based on blood flow presence/absence, and survival of skin flaps in hamsters have yet to be elucidated.Skin flap microcirculation can be evaluated by orthogonal polarization spectral (OPS) imaging. This recently developed microscopy method, originally described by Winkelman, ${ }^{12}$ can be used to non-invasively study the microcirculation with reflected light without any fluorescent dye. ${ }^{13}$ Olivier and co-workers showed that OPS technology is useful to directly observe microvascular blood flow in skin flaps and suggested post-operative monitoring of free-tissue transfers. ${ }^{14}$ The OPS technique has been incorporated into a portable device, the Cytoscan (Cytoscan, Cytometrics Inc., Philadelphia, PA, USA).

This study tested the efficiency of OPS imaging for the prognosis of flap viability, and compared the effects of acutely administered buflomedil and pentoxifylline on the microcirculation using a random-pattern skin flap survival test.

\section{MATERIALS AND METHODS}

Experiments were performed according to the protocols approved by the Ethical Committee of the State University of Rio de Janeiro, RJ, Brazil (CEA/215/2007) using 24 male 10-week-old Syrian golden hamsters (Mesocricetus auratus, Botucatu, São Paulo, SP, Brazil) weighing 110-130 g. Hamsters were divided into three groups. The control group received $0.1 \mathrm{ml}$ of vehicle $(\mathbf{C}, 0.9 \% \mathrm{NaCl})$, the buflomedil (B) group received $3 \mathrm{mg} / \mathrm{kg} /$ day of buflomedil (Abbott, São Paulo, Brazil), and the pentoxifylline (P) group received $14.5 \mathrm{mg} / \mathrm{kg} /$ day of pentoxifylline (Aventis Pharma, São Paulo, Brazil). All injections were administered intraperitoneally 1 hour before skin flap preparation and for 7 days post-operatively at 12-hour intervals. Animals received an appropriate laboratory diet of Nuvital (Nuvilab, Curitiba, PR, Brazil) and water provided ad libitum. Animals were anesthetized with $30 \mathrm{mg} / \mathrm{kg}$ of sodium pentobarbital (Pentobarbital sodique, Sanofi, Paris, France, $60 \mathrm{mg} / \mathrm{ml}$ ) intraperitoneally. Throughout the surgery and subsequent experiment, the temperature of the animals was maintained at $36.5^{\circ} \mathrm{C}$ with a heating pad controlled by a rectal thermistor (LTB 750 Thermostat System, Uppsala, Sweden). A dorsal tricotomy was performed, followed by local antisepsia with $70 \%$ alcohol. The dorsal flap was dissected, preserving the sacral arteries, and detached from its panniculus carnosus. The area was subsequently sutured to the dorsal region of the animal using simple stitches. The surgical protocol was based on the McFarlane skin flap model (Olivier et al.) ${ }^{14,15}$ adapted to hamsters.

\section{OPS imaging Protocol}

Each dorsal randomized skin flap measured $2 \times 6$ $\mathrm{cm}$ and was divided into 12 fields of $1 \mathrm{~cm}$ in diameter. Each of the two fields formed one band to be analyzed (Figure 1). An OPS probe, with a 10x objective and a final magnification of 450x, was applied to these fields from the base of the flap to the apex (Figure 1). The center of each field had a microscopic area of 700x550 $\mu \mathrm{m}$. Images of the microcirculation were video recorded, stored in VHS format, and subsequently processed by CapImage. ${ }^{16}$ Sterile mineral oil was applied between the probe and skin to improve the coupling and reliability of the readings.

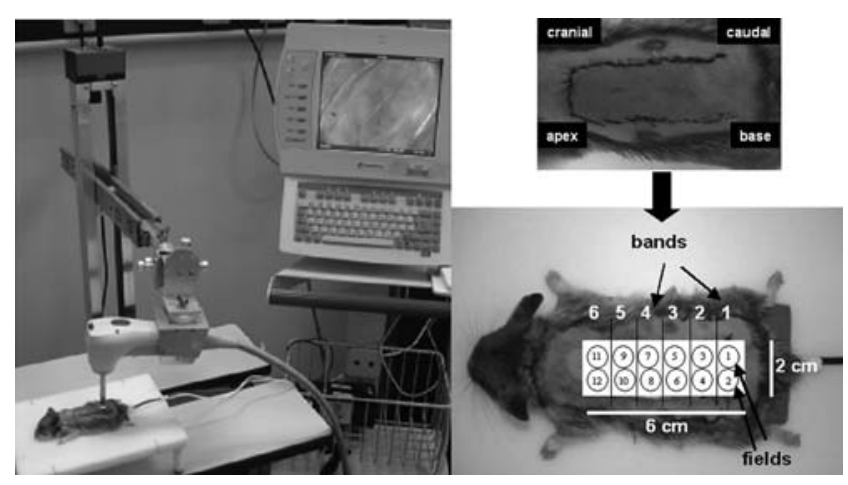

Figure 1 - Hamster skin flap model. Left side: the Cytoscan probe fixed by a mechanical device on the dorsal part of the animal. Right side: division of the skin flap into 12 fields from the caudal to cranial regions.

\section{Parameters Evaluated}

\section{Functional Capillary Density (FCD)}

Functional capillary density (FCD) was defined as the total length of capillaries with flowing red blood cells in the microscopic area $\left(\mathrm{mm} / \mathrm{mm}^{2}\right)$ under observation. This was measured at 1 and 24 hours after the surgical procedure. The mean values of the fields from each band are reported.

\section{Distance from the skin flap base to blood flow cessation (Dist with flow $)$}

The distance from the skin flap base to the blood flow cessation (Dist with flow ) field was measured at $1 \mathrm{~h}, 24 \mathrm{~h}$, and 7 days after surgery and compared to viable skin flaps.

\section{Percentage of viable skin flap area (\%VA)}

A transparent sheet was placed on the dorsal skin flap and drawings of the areas with blood flow and necrosis were performed. The percentage of viable area (\%VA) was calculated by dividing the healthy area by the total area on the seventh post-operative day using Autocad 2000 (Autodesk, San Rafael, USA) (Figure 2). 


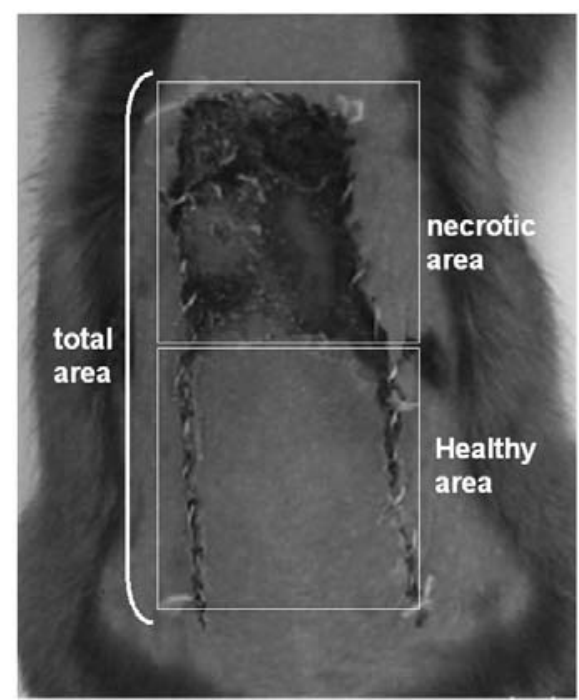

Figure 2 - Dorsal skin flap of the hamster on the seventh post-operative day. The percentage of viable area was obtained by dividing the healthy area by the total area

\section{Qualitative analysis of blood flow by OPS imaging}

The presence or absence of blood flow in the studied skin flaps was quantified in all 12 fields, grouped in bands (Figure 1) after 1 and $24 \mathrm{~h}$. The mean values of the fields from each band are reported. The data obtained were compared to the blood flow in the viable area observed on the seventh postoperative day.

\section{Statistical Analyses}

For clarity, the results are presented as the mean \pm standard error of the mean (S.E.M.). For statistical analysis, Mann-Whitney U tests, ANOVAs, and Wilcoxon matched pair tests were used to compare groups, and P-values $<0.05$ were considered as statistically significant.

\section{RESULTS}

All animals investigated did not demonstrate blood flow after the third band of the skin flap, independent of the postoperative time.

Figure 3 shows the FCD for the control, buflomedil, and pentoxifylline groups on bands I, II, and III 1 and 24 hours after the surgical procedure. A decrease in FCD was observed from band I to band III in all groups analyzed after 24 hours. The buflomedil group showed higher FCD values compared to the control or pentoxifylline group for each band at 1 and $24 \mathrm{~h}$. Conversely, no statistical differences were observed for Dist ${ }_{\text {with flow }}$ between the control, buflomedil, and pentoxifylline groups.

Although all groups displayed increased distances between $24 \mathrm{~h}$ and the seventh day, they reached similar final

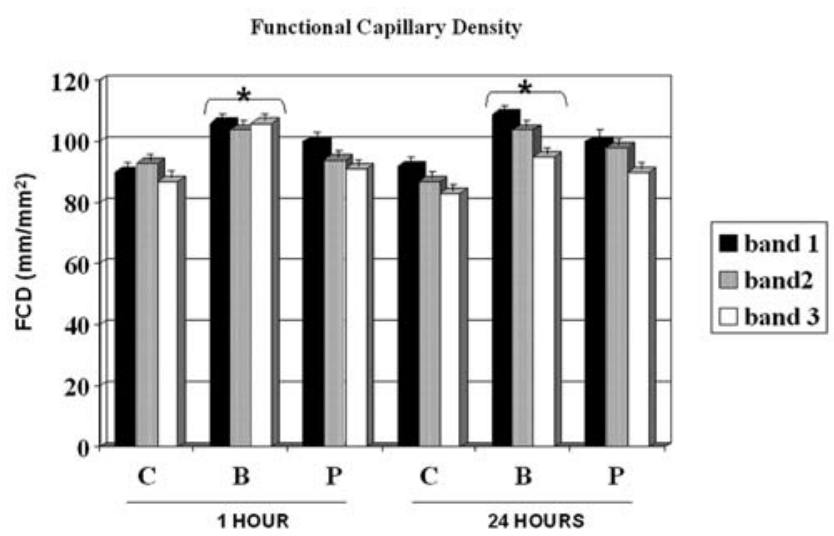

Figure 3 - The functional capillary density on bands I, II, and III among the control (C), Buflomedil (B), and Pentoxifylline (P) groups. These groups were evaluated 1 and $24 \mathrm{~h}$ after skin flap preparation. $* \mathrm{p}<0.05$ compared to controls

distances (control $=2.73 \mathrm{~cm}$, buflomedil $=2.78 \mathrm{~cm}$, and pentoxifylline $=2.70 \mathrm{~cm})($ Figure 4$)$.

The percentage of viable area is illustrated in Figure 5. The perfusion/non-perfusion interface was easily identified,

Distance from skin-flap base to blood flow cessation

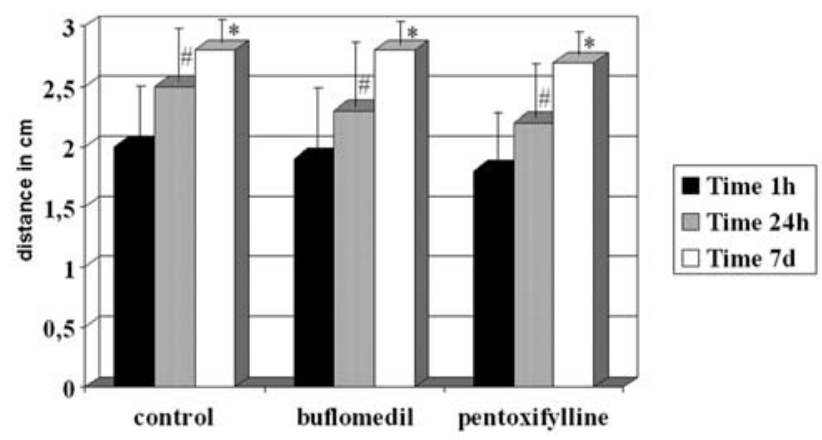

Figure 4 - Distance from the skin flap base to blood flow cessation in the control, Buflomedil, and Pentoxifylline groups. These groups were evaluated 1 (Time $1 \mathrm{~h}$ ) and 24 (Time 24h) hours and 7 (Time 7d) days after skin flap preparation. *,\# $\mathrm{p}<0.05$ compared to Time $1 \mathrm{~h}$

Percentage of viable skin-flap after 7 days

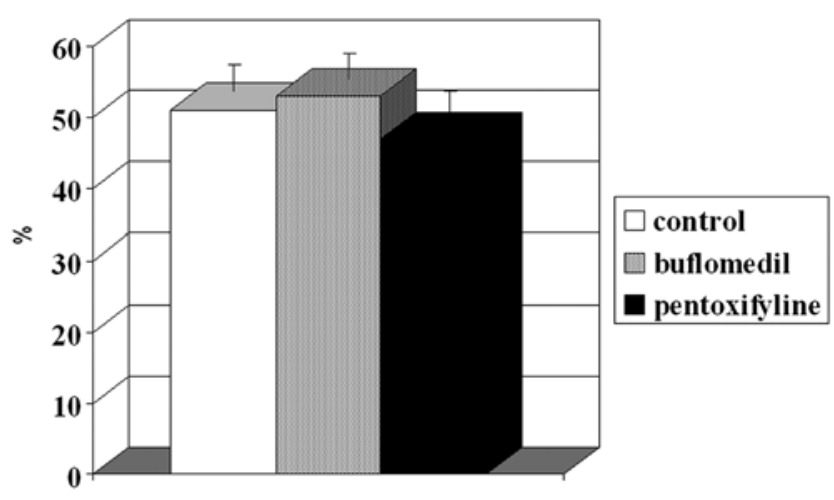

Figure 5 - Viable skin flap area on the seventh post-operative day 
and there was no difference in the percentage of viable areas among the control, buflomedil, and pentoxifylline groups (50.7, 52.9, and 47.0, respectively). Finally, the mean percentage of the preserved area was approximately $50 \%$ for all groups.

On the seventh post-operative day, we were able to confirm the presence of blood flow, which was detected after $1 \mathrm{~h}$ using OPS imaging of the first three bands for all groups. Using this technique, however, we were unable to correlate all areas that lacked blood flow with a given time line. For band II, an area of $100 \%$ in the control, buflomedil, and pentoxifylline groups without blood flow $1 \mathrm{~h}$ after surgery developed into perfused zones 7 days after surgery. The prediction of blood flow absence (in \%) after $1 \mathrm{~h}$ and on postoperative day 7 for the control, buflomedil, and pentoxifylline groups for band III is shown in Figure 6. Note that the percentage of fields without blood flow detected by Cytoscan in controls decreased from $75 \%$ after $1 \mathrm{~h}$ to $60 \%$ after 7 days. This corresponds to a prediction power of $80 \%$. The same pattern occurred for the buflomedil and pentoxifylline groups.

\section{Percentage of fields without blood flow on Band III}

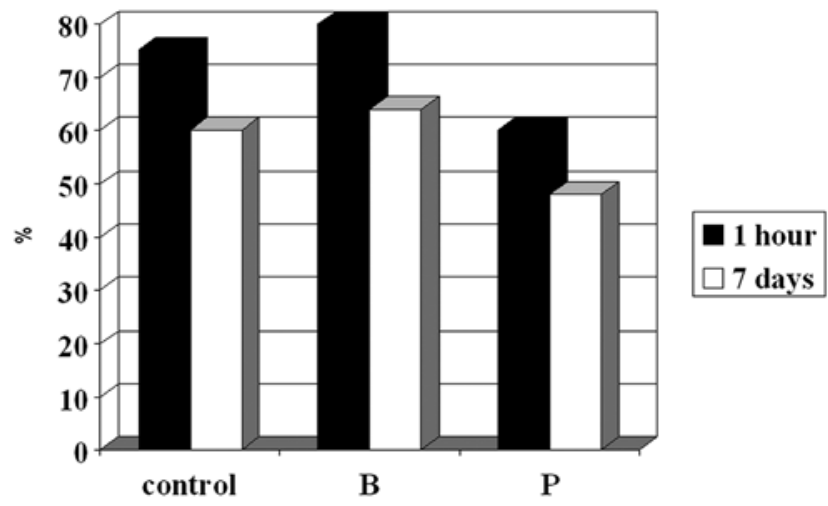

Figure 6 - Prediction by OPS imaging of the percentage of fields without blood flow after $1 \mathrm{~h}$ that persisted 7 days later

\section{DISCUSSION}

When a skin flap is raised, injury to the blood vessels and sympathetic nerves causes hemodynamic instability, leading to blood flow abnormality and a disturbance in tissue oxygenation. ${ }^{17}$ In this work, two approaches were used to evaluate skin flap success. We used buflomedil and pentoxifylline and determined their effects on the microcirculation and skin flap survival (FCD, Dist ${ }_{\text {with flow }}$, $\%$ VA), and the OPS imaging technique to predict flap viability over time following surgery.

Since significant microvascular damage is present during skin flap preparation, the development of early necrotic areas is expected. Indeed, all fields on bands IV, V, and VI did not present any blood flow, resulting in tissue death. The FCD decreased in all groups from band I to band III and was significantly lower on the distal part of the flap compared to its base after $24 \mathrm{~h}$. The buflomedil group demonstrated higher values of FCD compared to the control and pentoxifylline groups. These results are consistent with the results reported by Langer and colleagues, who validated the use of OPS imaging against intravital microscopy and measured FCD on the skin flaps of hairless mice. ${ }^{18}$ Harder et al. also showed a decrement in FCD in several segments from the base to the apex of the skin flaps of mice. ${ }^{19}$ Buflomedil has been shown to have positive effects on microvascular reperfusion injury by decreasing leukocyte adhesion. ${ }^{20}$ However, Szczesny et al. showed that buflomedil is ineffective in avoiding a decrease in the FCD of local skin blood perfusion during general anesthesia using intravital fluorescence microscopy in hairless mice. ${ }^{21}$ In addition, resting skin flux motion activity at the hallux in patients with intermittent claudication evaluated by laser Doppler fluxometry was not increased after buflomedil treatment. ${ }^{22}$ It is possible that the results presented herein could be explained by better buflomedil effects on the redistribution of blood flow after ischemia compared to pentoxifylline. In fact, Briguglio et al. demonstrated an attenuation of ischemia-induced histological loss and damage to pyramidal cells in rats treated with buflomedil. ${ }^{23}$ On the other hand, FDC showed favorable results and Dist ${ }_{\text {with flow }}$ did not change among the control, buflomedil, and pentoxifylline groups at any time point analyzed. For each group, increasing values of Dist ${ }_{\text {with flow }}$ were detected from 1 hour to 7 days. Conflicting results have been reported concerning the actions of buflomedil and pentoxifylline on surface length necrosis on flaps or microcirculation. Quirinia and colleagues did not find any differences in wound healing for buflomedil compared to the control (no treatment) in rats ${ }^{24}$; however, Kamler and et al. showed an acceleration of wound surface area reduction after chronic ischemia. ${ }^{25}$ On the other hand, pentoxifylline elicited improved cardiovascular autonomic function, but failed to reduce microalbuminuria in type 2 diabetic patients, revealing a microcirculatory defect. ${ }^{26}$

The percentage of viable area on the seventh day after the surgical procedure did not differ among the groups studied and remained at approximately 50\%, consistent with the buflomedil results described by Biondo-Simões et al. ${ }^{27}$ This result could be explained by the following scenarios. The treatment duration was not sufficient to produce favorable blood flow redistribution (treatment was initiated $1 \mathrm{~h}$ before surgery and lasted 7 days), allowing only acute effects to be detected. Bayat and colleagues chronically pretreated rats for 30 days with pentoxifylline before skin flap preparation 
and observed an increase in flap survival. ${ }^{28}$ Emrecan et al. showed that pentoxifylline could have an acute effect on the skeletal muscle of rabbits in an ischemia-reperfusion model. ${ }^{29}$ Our group selected buflomedil ( $3 \mathrm{mg} / \mathrm{kg} /$ day) and pentoxifylline $(14.5 \mathrm{mg} / \mathrm{kg} / \mathrm{day})$ administration for 7 days post-surgery to elucidate the acute drug effects.

Another possibility could be that buflomedil and pentoxifylline are not capable of improving the microcirculation without any previous impairment of this structure. A lower percentage of viable skin flap areas in pretreated rats has been demonstrated with nicotine, which decreases blood flow to peripheral vessels by $40 \%$. The percentage of viable areas was larger for the buflomedil and pentoxifylline groups than for rats administered nicotine. ${ }^{30}$ Finally, severe impairment of the microcirculatory network during the surgical procedure might interfere with drug action. It is well known that thin skin flaps may jeopardize the circulation. ${ }^{31}$ In the present study, the dorsal skin flap and sacral arteries containing the panniculus carnosus were preserved. It is likely, however, that some degree of arteriovenous shunting occurred over $24 \mathrm{~h}$ in the early and/or late post-operative periods, thereby limiting the skin survival in areas with marginal blood flow. ${ }^{32}$ Using a pig skin flap model, Kerrigan et al. observed that the dermal vessels of an ischemic island flap were dramatically affected. ${ }^{3}$ We also observed several distal random ischemic regions, which may have determined the final survival of the flap.

The Cytoscan was very effective in predicting skin flap viability. All fields in which blood flow was present after 1 and $24 \mathrm{~h}$ (detected by Cytoscan) remained viable 7 days after surgery.

Conversely, the prediction rate for fields without blood flow was not as effective. All fields without blood flow on band II and $20 \%$ of the fields on band III in all groups recovered after 7 days. Thus, the Cytoscan was more efficient in predicting fields without blood flow on band III, which had direct contact with the necrotic area and was subjected to unstable hemodynamics. It must be noted that some fields with unpredictable blood flow recovery will normally be present, ${ }^{33,34}$ and it should be emphasized that the OPS technique appeared to be more accurate than the clinical evaluation of skin flap necrosis. ${ }^{14}$ Other evaluations of microcirculation techniques also exist, such as intravital fluorescence microscopy, ${ }^{35}$ but the portability of this technique is limited. Laser Doppler flowmetry ${ }^{36}$ also appears to be a promising technique for use with OPS imaging.

\section{CONCLUSIONS}

Buflomedil presented higher values of FCD compared to the control and pentoxifylline groups in the skin flap hamster model. However, no differences were observed for the distance from the skin flap base to blood flow cessation or the percentage of viable skin flaps among groups.

Orthogonal polarization spectral imaging is a very useful tool to assess skin flap viability by counting fields with and without blood flow, showing the ability to confirm $100 \%$ of the areas with and $80 \%$ of the areas without flow over time.

\section{ACKNOWLEDGEMENTS}

The authors wish to thank Mrs. Cristiane Maria Simonato Conde and Miss Kelly Silva de Andrade for technical support.

\section{REFERENCES}

1. Cormack GC, Lamberty BGH. Concepts of territories. In: Cormack GC, Laberty BGH, eds. The arterial anatomy of skin flaps.1986; Edinburgh: Churchill Livingstone.

2. Erni D, Sakai H, Banic A, Tschopp HM, Intaglietta M. Quantitative assessment of microhemodynamics in ischemic skin flap tissue by intravital microscopy. Ann Plast Surg. 1999;43:405-14.

3. Kerrigan CL. Skin flap failure: pathophysiology. Plast Reconstr Surg. 1983;72:766-77.

4. Williams PB, Hankins DB, Layton CT, Phan T, Pratt MF. Long-term pretreatment with pentoxifylline increases random skin flap survival. Arch Otolaryngol Head Neck Surg. 1994;120:65-71.

5. Galla TJ, Saetzler RK, Hammersen F, Messmer K. Increase in skinflap survival by the vasoactive drug buflomedil. Plast Reconstr Surg. $1991 ; 87: 130-6$
6. Roth AG, Briggs PC, Jones EW, Heckler FR. Augmentation of skin flap survival by parenteral pentoxifylline. Br J Plast Surg. 1988;41:515-20.

7. Dias LC, Foustanos A, Carreirão S, Filho SS, Pitanguy I. Influência do buflomedil na viabilidade de retalhos cutâneos. Revista Brasileira de Cirurgia. 1990;80:49-53.

8. Vanhoutte PM, Aarhus LL, Coen E, Lorenz RR, Rimele TJ, Verbeuren TJ. Effects of buflomedil on the responsiveness of canine vascular smooth muscle. J Pharmacol Exp Ther. 1983;227:613-20.

9. Clissold SP, Lynch S, Sorkin EM. Buflomedil. A review of its pharmacodynamic and pharmacokinetic properties, and therapeutic efficacy in peripheral and cerebral vascular diseases. Drugs. 1987;33:430-60.

10. Kishi M, Tanaka H, Seiyama A, Takaoka M, Matsuoka T, Yoshioka T, et al. Pentoxifylline attenuates reperfusion injury in skeletal muscle after partial ischemia. Am J Physiol. 1998;274:H1435-H1442. 
11. Frampton JE, Brogden RN. Pentoxifylline (oxpentifylline). A review of its therapeutic efficacy in the management of peripheral vascular and cerebrovascular disorders. Drugs Aging. 1995;7:480-503.

12. Winkelman JW. Apparatus and method for in vivo analysis of red and white blood cells indices. [4,998,533]. 2008. U.S.A. 1991. Ref Type: Patent

13. Groner W, Winkelman JW, Harris AG, Ince C, Bouma GJ, Messmer K, et al. Orthogonal polarization spectral imaging: a new method for study of the microcirculation. Nat Med. 1999;5:1209-12.

14. Olivier WA, Hazen A, Levine JP, Soltanian H, Chung S, Gurtner GC. Reliable assessment of skin flap viability using orthogonal polarization imaging. Plast Reconstr Surg. 2003;112:547-55.

15. MCFarlane RM, Deyoung G, Henry RA. The design of a pedicle flap in the rat to study necrosis and its prevention. Plast Reconstr Surg. 1965;35:177-82.

16. Klyscz T, Junger M, Jung F, Zeintl H. [Cap image--a new kind of computer-assisted video image analysis system for dynamic capillary microscopy]. Biomed Tech (Berl). 1997;42:168-75.

17. Finseth F, Adelberg MG. Experimental work with isoxuprine for prevention of skin flap necrosis and for treatment of the failing flap. Plast Reconstr Surg. 1979;63:94-100.

18. Langer S, Biberthaler P, Harris AG, Steinau HU, Messmer K. In vivo monitoring of microvessels in skin flaps: introduction of a novel technique. Microsurgery. 2001;21:317-24.

19. Harder Y, Amon M, Erni D, Menger MD. Evolution of ischemic tissue injury in a random pattern flap: a new mouse model using intravital microscopy. J Surg Res. 2004;121:197-205.

20. Menger MD, Steiner D, Pelikan S, Messmer K. Buflomedil hydrochloride attenuates tourniquet-induced microvascular reperfusion injury in striated muscle. Int J Microcirc Clin Exp. 1994;14:296-302.

21. Szczesny G, Veihelmann A, Nolte D, Olszewski WL, Messmer K. Heparin protects local skin microcirculation in 210 minutes-long intravital microscopy observations under general anaesthesia. Eur J Med Res. 2001;6:175-80.

22. Van den BP, Maurel A. A placebo-controlled study of the effects of intravenous Buflomedil on foot skin microcirculation in patients with severe intermittent claudication. Angiology. 1998;49:105-14.

23. Briguglio FS, Mondello MR, Galluzzo M, Raneri E, De PA, Saija A, et al. Protective effect of buflomedil in a rat model of moderate cerebral ischemia. Arzneimittelforschung. 2005;55:437-42.

24. Quirinia A, Gottrup F, Viidik A. Failure of buflomedil to improve wound healing in ischaemic skin flaps. Scand J Plast Reconstr Surg Hand Surg. 1996;30:81-7.
25. Kamler M, Lehr HA, Barker JH, Saetzler RK, Galla TJ, Messmer K. Impact of ischemia on tissue oxygenation and wound healing: intravital microscopic studies on the hairless mouse ear model. Eur Surg Res. 1993;25:30-7.

26. Laczy B, Cseh J, Mohas M, Marko L, Tamasko M, Koszegi T, et al. Effects of pentoxifylline and pentosan polysulphate combination therapy on diabetic neuropathy in type 2 diabetes mellitus. Acta Diabetol. 2009;46:105-11.

27. Biondo-Simões MLP, Greca FH, Paula JB, Chin EWK, Santos EAA, Talhschmidt FL. Effect of buflomedil on ischemic skin flaps:experimental study in rats. Acta Cir Bras. 2000;15[suppl 3],36-40.

28. Bayat M, Chelcheraghi F, Piryaei A, Rakhshan M, Mohseniefar Z, Rezaie F, et al. The effect of 30-day pretreatment with pentoxifylline on the survival of a random skin flap in the rat: an ultrastructural and biomechanical evaluation. Med Sci Monit. 2006;12:BR201-BR207.

29. Emrecan B, Tulukoglu E, Bozok S, Aksun M, Yagdi S, Ozcan AV, et al. Iloprost and pentoxifylline attenuate ischemia-reperfusion injury in skeletal muscle in rabbit model. Ulus Travma Acil Cerrahi Derg. 2008; $14: 182-7$

30. Mauad RJ, Jr., Shimizu MH, Mauad T, de Tolosa EM. Buflomedil and pentoxifylline in the viability of dorsal cutaneous flaps of rats treated with nicotine. J Plast Reconstr Aesthet Surg. 2006;59:387-92.

31. Yazar S, Guzel MZ, Aydin Y, Arslan H, Demir M. Demonstration of circulation haemodynamics in random pattern thinned skin flap (an experimental study). J Plast Reconstr Aesthet Surg. 2008;61:1368-77. Epub 2008 Jan 14.

32. Reinisch JF. The pathophysiology of skin flap circulation. The delay phenomenon. Plast Reconstr Surg. 1974;54:585-98.

33. Jia C, Chen B, Su Y. [Prediction of skin flap viability by laser Doppler scanning]. Zhonghua Zheng Xing Shao Shang Wai Ke Za Zhi. 1996;12:410-1.

34. Payette JR, Kohlenberg E, Leonardi L, Pabbies A, Kerr P, Liu KZ, et al. Assessment of skin flaps using optically based methods for measuring blood flow and oxygenation. Plast Reconstr Surg. 2005;115:539-46.

35. Lecoq JP, Joris JL, Nelissen XP, Lamy ML, Heymans OY. Effect of adrenergic stimulation on cutaneous microcirculation immediately after surgical adventitiectomy in a rat skin flap model. Microsurgery. 2008;28:480-6.

36. Goertz O, Kirschner MH, Lilienfein H, Babilas P, Steinau HU, Andree $\mathrm{C}$, et al. Effects of maleimide-polyethylene glycol-modified human hemoglobin (MP4) on tissue necrosis in SKH1-hr hairless mice. Eur J Med Res. 2009;14:123-9. 